\title{
A laboratory study of rheological properties of mudflows in Hangzhou Bay, China
}

\author{
Zhenhua HUANG ${ }^{1,2}$ and Huhe Aode ${ }^{3}$
}

\begin{abstract}
A laboratory study of the rheology of mudflows in Hangzhou Bay, China, is reported in this paper. Both the steady and oscillatory (dynamic) rheological properties are studied using RMS-605 rheometer. A Dual-Bingham model is proposed for analyzing flow curves and compared with Worrall-Tuliani model. It is found that Dual-Bingham plastic rheological model is easier to implement than Worrall-Tuliani model and can provide satisfactory representations of the steady mudflows in Hangzhou Bay and other published data. The dependence of the yield stress and viscosity on sediment concentration is discussed based on the data from Hangzhou Bay mud and other published data. For the dynamic rheological properties of Hangzhou Bay mud, empirical expressions for elastic modulus and dynamic viscosity are provided in the form of exponential functions of sediment volume concentration, and comparisons with other published data also discussed.
\end{abstract}

Key Words: Mud rheology, Cohesive sediments, Rheological models, Mudflows, Hangzhou Bay mud

\section{Introduction}

Natural mud in river beds, lake beds, or coastal seabed is a cohesive material composed primarily of fine-grained minerals. Understanding cohesive sediment transport under complex flow conditions is of major importance in many coastal projects related to navigation channels, harbors, shoreline protections, and water quality control in coastal waters. Before undertaking computational modeling of cohesive sediment transport, measurements of grain-size distribution, chemical composition, and rheological properties of cohesive sediment at project sites should be performed. An inadequate representation of the physical properties of cohesive sediment may lead to greater uncertainties in the prediction of sediment transport than an inadequate representation in hydrodynamics (Whitehouse et al., 2000). When there is no field or laboratory measurements available, rheological properties of mudflows at project sites may be derived from those with similar size distribution, clay content and sediment concentration.

The study of rheological behavior of natural mud is concerned with flows or deformations of a mud sample experiencing an external forcing. Variable amounts of seawater are trapped in the mineral structure of natural mud by attracting force. As a result, natural mud shows viscous behaviors through a variable range of water content. When dried, mud can be hardened and show pure elastic behavior. However, natural mud is a visco-elastic material in its natural state. It is important to have an adequate constitutive equation to describe both the viscous and elastic responses of natural mud to various loads. Unfortunately, at the present time there is no good in situ method available to measure the rheology of naturally-deposited mud. Meaningful in situ measurements are difficult to perform without disturbing the

\footnotetext{
${ }^{1}$ Asst. Prof., School of Civil and Environmental Engineering, Nanyang Technological University, Republic of Singapore, +65 6791 9676, E-mail:zhhuang@ntu.edu.sg.

${ }^{2}$ Earth Observatory of Singapore, Nanyang Technological University, Republic of Singapore

${ }^{3}$ Prof. Emeritus, Institute of Mechanics, Chinese Academy of Sciences, Beijing 100190, China

Note: The original manuscript of this paper was received in Nov. 2008. The revised version was received in Sept. 2009. Discussion open until Dec. 2010.
} 
natural mud deposited in seabed. Mud samples used in laboratory tests often are severely disturbed. Therefore the microstructure of mud samples in laboratory tests may significantly differ from that of the natural mud deposited in seabed. In laboratory studies, care must be taken to keep the test conditions as close to the natural conditions as possible. Factors that we need to considerer include seawater salinity, sediment concentration, consolidation time, temperature, etc.

The external forcing on the mud layer in river beds or seabed is in general very complicated. Wind waves in rivers are generally small, thus flows can be approximated adequately by quasi-steady ones, with the external forcing on the mud in the river bed being nearly unidirectional. Flows in coastal water are strongly influenced by the presence of ocean waves. A thin oscillatory boundary layer near seabed exists (Jorgen and Deigaard,1992), resulting in cycling shear stresses much larger than the unidirectional shear stresses due to ocean currents.

In the past half century, a rich literature has been built up for cohensionless sediment transport (Jorgen and Deigaard (1992) for a review on this topic), but more research need to be done on the transport mechanisms of cohesive sediments. Even though there are quite a few published papers on the numerical simulations of cohesive sediment transport (Malcherek et al., 1996; Maa and Mehta, 1990; Mayne et al., 2002 ; etc.), dynamic rheological data for natural mud are rare-the published data for the rheological properties of mud motions focused primarily on the rheology of steady mudflows. (Coussot (1997) for excellent reviews on current knowledge in non-oscillatory mudflows, and Coussot (2007) for a review on rheology for both steady and oscillatory mudflows.) Published data on dynamic rheology of natural mud are rare. To our knowledge, only a few published papers reported some rheological measurements on the oscillatory properties of natural mud (for example, Jiang and Metha, 1995; Van Kessel and Blom, 1998). Jiang and Metha (1995) analyzed natural mud samples from several places in India and US, and examined the dependence of complex viscosity on sediment concentration. Van Kessel and Blom (1999) examined effects of strain amplitude on the dynamic rheological properties of two mud samples. In this study, the rheological properties of natural mud from Hangzhou Bay in China are analyzed based on the unpublished results of Huhe and Huang (1994a). Main goals of the present study are (i) to provide an easy-to-use rheological model for numerical models of cohesive mud transport, and (ii) to contribute another valuable data set to the small existing pool of dynamic rheological data for natural mud.

Relevant existing rheological models are first briefly reviewed in chapter 2. Description of Hangzhou Bay mud, preparation of mud samples, equipment and testing method are given in chapter 3 . Test results are summarized and discussed in chapter 4, where Worrall-Tuliani model (Worrall and Tuliani, 1964; Toorman, 1994) and Dual-Bingham plastic model are introduced and to analyze the flow curves of our experiments and those from other published data. The dynamic rheology of Hangzhou Bay mud is also discussed in chapter 4. Finally, main conclusions are given in chapter 5.

\section{Rheological models for steady or oscillatary mudflows}

If mud is treated as continuum media, the following equations can be used to model the mudflow (Piedra-Cueva, 1993; Malcherek et al., 1996; Ng and Zhang, 2002; etc.)

$$
\begin{gathered}
\frac{\partial u_{i}}{\partial x_{i}}=0, \\
\rho \frac{D u_{i}}{D t}=-\frac{\partial p}{\partial x_{i}}+\frac{\partial \tau_{i j}}{\partial x_{j}},
\end{gathered}
$$

where $u_{i}$ is the velocity component in $x_{i}$-direction, $t$ the time, $p$ the dynamic pressure in mudflow, and $\rho$ the mud density. The stress tensor $\tau_{i j}$ is related to the mud property by certain constitutive equation. Depending on the nature of the mudflow, a large number of constitutive equations are available for the stress tensor $\tau_{i j}$.

It is usually assumed that mud samples are isotropic. Under this assumption, the constitutive equation for the stress tensor $\tau_{i j}$ can be constructed from one dimensional rheological experiment. For one dimensional mudflows, the simplest relation between the shear stress and the deformation can be described by $\tau=\tau(\gamma, \dot{\gamma})$, where $\gamma$ and $\dot{\gamma}$ are shear strain and shear rate, respectively. Three models employed in this study are briefly reviewed first for completeness. 


\subsection{Rheology of steady mudflows}

One of the widely-used models for steady mudflows is Herschel-Bulkley model or generalized Bingham plastic model (Barnes et al., 1989; Coussot, 1997; Huang and Garcia, 1998; Whitehouse et al., 2000; etc.). Herschel-Bulkley model is a two-parameter rheological model, which relates the shear rate $\dot{\gamma}$ to the shear stress $\tau$ by

$$
\tau=\tau_{0}+\eta_{B} \dot{\gamma}^{n},|\tau| \geq \tau_{0}, \text { and } \dot{\gamma}=0,|\tau|<\tau_{0},
$$

In Eq. (3) $\tau_{0}$ is the so-called yield stress (the shear stress at $\dot{\gamma}=0$ ), $\eta_{B}$ is a parameter related to the mud viscosity, and $n$ is the so-called flow index. When $n<1$, mud exhibits shear-thinning behaviour; when $n>1$, mud exhibits a shear-thickening behaviour (Whitehouse et al., 2000). For Herschel-Bulkley model, an apparent viscosity $\eta_{a}$ is defined by Eq. (4)

$$
\eta_{a}=\frac{\tau_{0}}{\dot{\gamma}}+\eta_{B} \dot{\gamma}^{n-1},|\tau| \geq \tau_{0} .
$$

There is no definition for the apparent viscosity when $|\tau|<\tau_{0}$. Three special cases can be derived from Herschel-Bulkley model: (1) general power law model when $\tau_{0}=0$ and $n \neq 1$, (2) Newtonian model when $\tau_{0}=0$ and $n=1$, and (3) Bingham plastic model when $\tau_{0}>0$ and $n=1$. Bingham plastic model has been widely used in the study of cohesive sediment transport in coastal waters (Mei and Liu, 1984; Shibabyama and Bijker, 1989; Liu and Mei, 1989; Bai et al., 2002; etc.).

It has been found in the literature that the above models sometimes cannot fit measured flow curves with satisfactory accuracy in the region of low shear rate (Julien and Lan, 1991; Toorman, 1994; etc.). In particular, Toorman (1994) examined the following Worrall-Tuliani model proposed by Worrall and Tuliani (1964) for clay suspensions (Malcherek et al., 1996; Mayne et al., 2002)

$$
\tau=\tau_{0}+\mu_{\infty} \dot{\gamma}+\frac{\left(\eta_{0}-\eta_{\infty}\right) \dot{\gamma}}{1+\beta \dot{\gamma}}, \beta=\frac{\eta_{0}-\eta_{\infty}}{\tau_{\infty}-\tau_{0}} .
$$

He found that Worrall-Tuliani model can better fit the measured flow curves reported in his paper over a relatively-wide range of shear rate. In Eq. (5), $\tau_{0}$ is Worrall-Tuliani true yield stress (the stress at $\dot{\gamma}=0$ ) and $\tau_{\infty}$ is Worrall-Tuliani Bingham yield stress. The two viscosities, $\eta_{0}$ and $\eta_{\infty}$, are the viscosities at low shear rate and high shear rate, respectively. Toorman (1994) called $\eta_{\infty}$ the Bingham viscosity.

Huhe and Huang (1994a) proposed the following Dual-Bingham plastic model

$$
\left\{\begin{array}{l}
\tau=\tau_{0}+\eta_{0} \dot{\gamma}, \quad \dot{\gamma}<\dot{\gamma}_{c} \\
\tau=\tau_{\infty}+\eta_{\infty} \dot{\gamma}, \quad \dot{\gamma} \geq \dot{\gamma}_{c}
\end{array},\right.
$$

where $\tau_{0}$ is the Dual-Bingham true yield stress and $\tau_{\infty}$ is the Dual-Bingham apparent yield stress. Similarly, $\eta_{0}$ is the Dual-Bingham initial viscosity and $\eta_{\infty}$ is the Dual-Bingham apparent viscosity. The shear rate $\dot{\gamma}_{c}$ is a critical shear rate, which is determined by

$$
\dot{\gamma}_{c}=\frac{\tau_{\infty}-\tau_{0}}{\eta_{0}-\eta_{\infty}} .
$$

Note that Dual-Bingham model is also a four parameter model. Even though in the limit of $\dot{\gamma} \rightarrow 0$ or $\dot{\gamma} \rightarrow \infty$ the Worrall-Tuliani model given in Eq. (5) can approach the Dual-Bingham plastic model described by Eq. (6), we shall show later that the use of Dual-Bingham model is easier to implement and the fit to measured flow curves is better than Worrall-Tuliani model for the Hangzhou Bay mud samples.

\subsection{Remarks on the determination of yield stress}

By definition, a yield stress is the critical stress below which the shear rate is exactly zero. In practice, the yield stress is determined at $\dot{\gamma}=0$ on a flow curve. There is a debate in the literature on the existence of a "true" yield stress, even though it is one of the most widely used rheological characteristics of natural 
mud in practice. In this study, the existence of a yield stress is assumed for mud. However, when measuring the flow curves using stress-controlled rheometer like RMS605, the shear rate can never be zero. Therefore, the yield stress must be determined by an extrapolation of the measured flow curve to zero shear rate. As a result, the yield stress is meaningful only for the rheological model used to perform the extrapolation. This is one of the reasons why there is a debate on the existence of unique yields stress. For example, James et al. (1987) used Casson's equation (Casson,1957) to define a nonlinear yield stress at zero shear rate and used Bingham model to determine the Bingham yield stress by an extrapolation of the linear segment of a flow curve at higher shear rate. Julien and Lan (1991) used a quadratic model to determine the yield stress in their paper. In general, yield stresses obtained by different rheological models should not be directly compared with each other. The great scatter observed in the published data of yield stress is due partially to the different choices in selecting a rheological model and the segment of the flow curve for extrapolation. Dual-Bingham model acknowledges the fact that the yield stress obtained by extrapolating the linear segment of the flow curve in the range of higher shear rate differs from that obtained by extrapolating the segment in the range of lower shear rate.

\subsection{Rheology of oscillatory mudflows: Kelvin-Voigt visco-elastic model}

The dynamic rheology of coastal mud determines how mud would response to the action of cyclic loads due to ocean waves. One of the widely-used models for the dynamic rheology of coastal mud is the socalled Kelvin-Voigt visco-elastic model (Maa and Mehta, 1988; Shibayama and Bijker, 1989; Maa and Mehta, 1990; Shibayama and An, 1993; Piedra-Cueva, 1993; Foda et al,, 1993; Song and Jiang, 1998; Whitehouse et al., 2000; Ng and Zhang, 2007; Zhang et al., 2007, etc., for applications of Kelvin-Voigt model in cohesive sediment transport). For one dimensional flow, Kelvin-Voigt model is described by Eq. (8)

$$
\tau=G^{\prime} \gamma+\eta \dot{\gamma}
$$

where $\gamma$ is the shear deformation, $\dot{\gamma}$ the shear rate, $\eta$ the dynamic viscosity, and $G^{\prime}$ the elastic shear modulus. For pure solids, $\eta \rightarrow \infty$; for pure fluids, $G^{\prime} \rightarrow 0$. The constitutive equation (8) says that the shear stress in mud will produce both viscous and elastic responses. Mud will exhibit certain features of viscous flows under constant stress, but a portion of mechanical energy contained in the mud flows can be conserved and recovered after stress is released. If both $G^{\prime}$ and $\eta$ are independent of $\gamma$ and $\dot{\gamma}$, the rheological model is linear with respect to the oscillation frequency; otherwise, the rheological model is nonlinear.

In next two sections, the rheological behaviors of both steady and oscillatory mudflows are studied experimentally for Hangzhou Bay mud. The rheology of steady mudflows will be analyzed by both Worrall-Tuliani model and Dual-Bingham model, while the dynamic rheology will be analyzed by Kelvin-Voigt visco-elastic model.

\section{Materials and methods}

\subsection{Materials}

Natural mud samples used in this study were taken from two sites in Hangzhou Bay, where two trial navigation channels were constructed to study the refill rate of muddy sediment under complex wavecurrent actions. Some basic properties of Hangzhou Bay mud are summarized in Table 1. Average tidal range at Da-Yang-San in Hangzhou Bay is $2.8 \mathrm{~m}$ and maximum tidal range can go up to $4.3 \mathrm{~m}$, and the typical maximum ebb current and flooding current in this area are $3.1 \mathrm{~m} / \mathrm{s}$ and $2.6 \mathrm{~m} / \mathrm{s}$ (Chen and Gu, 2000), respectively. At low tide, the water depth is $7.4 \mathrm{~m}$ at the site of the east trial channel and $8.9 \mathrm{~m}$ at the site of the west trial channel (Jin and $\mathrm{Yu}, 1999$ ). For moderate waves of period $T=6.28 \mathrm{~s}$ (angular frequency $\omega=1 \mathrm{rad} / \mathrm{s}$ ) and height $H=2 \mathrm{~m}$, typical wave orbital velocity is about $2 \mathrm{~m} / \mathrm{s}$, implying that coastal mud deposited in seabed will be subject to strong oscillatory loads in most of the time. Therefore, laboratory studies of rheological properties of both steady and dynamic mudflows are needed to model the transport of costal cohesive mud. 
Table 1 Size distribution, grain density and clay content

\begin{tabular}{|c|c|c|c|c|c|}
\hline Sites of the natural mud & $\begin{array}{c}\text { Density of sediment } \\
\text { grains } \rho_{s}\left(\mathrm{~kg} / \mathrm{m}^{3}\right)\end{array}$ & Clay $(\%)$ & $D_{38}(\mathrm{~mm})$ & $D_{50}(\mathrm{~mm})$ & $D_{84}(\mathrm{~mm})$ \\
\hline East channel & 2704 & 37.7 & 0.005 & 0.0097 & 0.03 \\
\hline West channel & 2684 & 33.6 & 0.0066 & 0.011 & 0.034 \\
\hline
\end{tabular}

\subsection{Preparation of mud samples}

For our rheology tests, small amounts of mud samples were taken from the well-mixed mud-water mixtures with different densities. Seven mud samples of different mass concentrations (or sediment volume concentrations) were prepared in a large container by mixing the original mud samples taken from Hangzhou Bay with different amounts of salty water of $15 \%$ salinity. When taking the mud samples for rheology tests, the mud in the container was first mixed from top to bottom to make sure the density of the mud was uniform in the container. The details of the mud samples and test program are summarized in Table 2. During our tests, sample temperature was controlled at $15^{\circ} \mathrm{C}$. It is well-known that the microstructure of mud samples depends strongly on consolidation process (Whitehouse et al., 2000). After the clay-water materials are mixed, the microstructure in the mud sample has already been changed, thus certain consolidation time is needed for the mud to restore its microstructure. Since the consolidation time has noticeable effects on the rheological properties of mud samples, especially on those of low sediment concentration, preliminary tests were done for mud samples A1 and A3 to examine effects of the consolidation time on the measured flow curves. Three consolidation times $(5,10$ and 15 minutes) were examined, and some effects of the consolidation time on the measured flow curves were observed, especially with the sample A3. With the effects of consolidation process in mind, for most of our tests we started all our tests 5 minutes after the mud samples had been put in the rheometer tool, except those samples of very low concentration (the deposition process was found to be very fast for those samples).

Table 2 Test programme for RMS- 605 : Salinity $=1.5 \%$; Temperature $=15^{\circ} \mathrm{C}$

\begin{tabular}{|c|c|c|c|c|c|}
\hline \multirow{4}{*}{$\begin{array}{c}\text { Sample } \\
\text { sites }\end{array}$} & $\begin{array}{c}\text { Mud } \\
\text { sample } \\
\text { labels }\end{array}$ & $\begin{array}{c}\text { Mass } \\
\text { concentration } \\
S\left(\mathrm{~kg} / \mathrm{m}^{3}\right)\end{array}$ & $\begin{array}{c}\text { Volume } \\
\text { concentration } \\
C_{V}\end{array}$ & $\begin{array}{c}\text { Mud sample } \\
\text { density } \\
\rho\left(\mathrm{kg} / \mathrm{m}^{3}\right)\end{array}$ & $\begin{array}{c}\text { Consolidation } \\
\text { time (min) }\end{array}$ \\
\hline \multirow{4}{*}{$\begin{array}{c}\text { East } \\
\text { channel }\end{array}$} & $\mathrm{A} 0$ & 921 & 0.340 & 1590 & 5 \\
\cline { 2 - 6 } & $\mathrm{A} 1$ & 640 & 0.237 & 1414 & $5,10,15$ \\
\cline { 2 - 6 } & $\mathrm{A} 2$ & 544 & 0.201 & 1356 & $5,10,15$ \\
\cline { 2 - 6 } & $\mathrm{A} 3$ & 467 & 0.173 & 1306 & 5 \\
\cline { 2 - 6 } & $\mathrm{A} 4$ & 376 & 0.139 & 1251 & 5 \\
\cline { 2 - 6 } & $\mathrm{A} 5$ & 208 & 0.077 & 1145 & 5 \\
\hline \multirow{4}{*}{$\begin{array}{c}\text { West } \\
\text { channel }\end{array}$} & $\mathrm{B} 0$ & 1000 & 0.370 & 1634 & 5 \\
\cline { 2 - 6 } & $\mathrm{B} 1$ & 630 & 0.233 & 1403 & 5 \\
\cline { 2 - 6 } & $\mathrm{B} 2$ & 547 & 0.202 & 1352 & 5 \\
\cline { 2 - 6 } & $\mathrm{B} 3$ & 464 & 0.171 & 1300 & 5 \\
\cline { 2 - 6 } & $\mathrm{B} 4$ & 375 & 0.150 & 1246 & 5 \\
\cline { 2 - 6 } & $\mathrm{B} 5$ & 230 & 0.084 & 1155 & \\
\hline
\end{tabular}

3.3 Equipment for rheological tests

Rheometric Scientific RMS-605 rheometer was used in either cone/plate mode (for the first two densest mud samples in each group) or cylindrical mode (for other samples) to study both the steady and dynamic rheological properties of mudflows. The diameter of the mud sample was $25 \mathrm{~mm}$. Only the one-way flow curve was measured. No special end effect correction other than that comes with the system software was applied. This rheometer has a range of shear rate $10^{-3}<\dot{\gamma}<10^{2} 1 / \mathrm{s}$ and a range of viscosity $10<\eta<10^{8}$ Pa.s. The accuracy of the rheometer is $0.1 \%$. The shear rate range $10^{-3}<\dot{\gamma}<10^{2} 1 / \mathrm{s}$ was scanned within $300 \mathrm{~s}$ in our experiments. To study the dynamic rheology, frequency sweep tests were performed. A small cyclic shear deformation of frequency $\omega$ was used to measure the rheological properties of oscillatory mudflows. In our experiments, the frequency $\omega$ varied from $0.01 \mathrm{rad} / \mathrm{s}$ to $100 \mathrm{rad} / \mathrm{s}$. 


\section{Results and discussion}

4.1 Rheological behaviors of steady mudflows

Shown in Fig. 1(a) and Fig. 1(b) are the flow curves of Hangzhou Bay mud for east channel and west channel, respectively. Note that the apparent viscosity defined by $\tau / \dot{\gamma}$ decreases with the shear rate $\dot{\gamma}$. If the flow curves were analyzed by Herschel-Bulkley model, the shear-thinning phenomena (flow index $n<1)$ would exist in the high shear-rate portion of the flow curve. The basic features of our flow curves are in agreement with other published data (O'Brien and Julien, 1988; Huang and Huhe, 1994b; Komatina and Jovanovic, 1997). In general, the shear stress increases with increasing shear rate for the same mud sample, and shear stress increases with mud concentration at the same shear rate. In low shear rate region, the shear stress keeps decreasing with decreasing shear rate, indicating the difficulty in measuring yield stress at very low shear rate. In practice, yield stress is determined by an extrapolation which extends the measured flow curve to zero shear rate by using a chosen rheological model. Three models were considered in analyzing the measured flow curves.
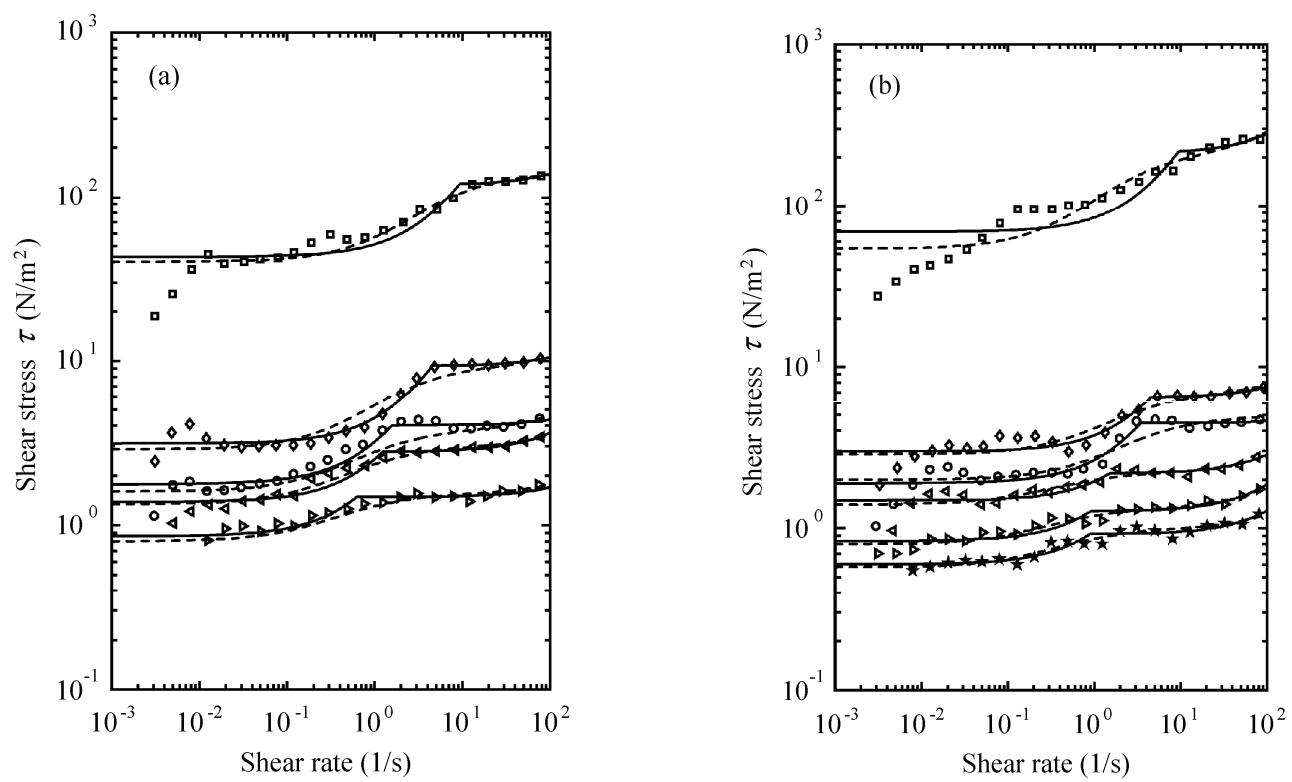

Fig. 1 Flow curves of the mud samples from the East channel (a) and the West channel (b) in Hangzhou Bay. For the East channel: $C_{v}=0.34$ (squares), 0.237(circles), 0.201(right triangles), 0.173 (left triangles), and 0.136(hexagram); For the West channel: $C_{v}=0.37$ (squares), 0.233(circles), 0.202(right triangles), 0.171(left triangles), and 0.150 (hexagram), and 0.084 (down triangles). Fitting curves: Dual-Bingham model (solid lines) and Worrall-Tuliani model (dashed lines)

We first examined Herschel-Bulkley model (with Bingham model being a special case). For the mud samples of very low sediment concentrations Bingham model could provide satisfactory description of flow curves. However, for other mud samples it was not possible to use a single model to describe the measured flow curves. Even though it is impossible to use a single Herschel-Bulkley model to describe the flow curves, it is possible to identify two flow regimes (low shear rate regime and high shear rate regime) and to employ Bingham model for each regime, i.e., to use a Dual-Bingham mode described by Eq. (6). We also examined Worrall-Tuliani model as described by Eq. (5). Both Dual-Bingham model and Worrall-Tuliani model are four parameter models, thus a least square minimization method is needed to find the four model parameters, $X=\left(\tau_{0}, \eta_{0}, \tau_{\infty}, \eta_{\infty}\right)$, from the measured flow curves.

MATLAB function LSQNONLIN was used in this study to carry out the nonlinear least-square data fitting. From our experience in using Worrall-Tuliani model, we found that initial guesses of the four 
model parameters as well as their lower and upper bonds are crucial for a successful nonlinear data fitting, especially for those mud samples of low sediment concentrations. Without specifying appropriate lower and upper bonds for the four model parameters, LSQNONLIN may fail to find the four model parameters in Worrall-Tuliani Model. On the other hand, Dual-Bingham model is a quasi-linear model. Data fitting using Dual-Bingham model is not sensitive to the initial guesses of the four model parameters and no lower and higher bounds are needed for the four model parameters in Dual-Bingham model. In our analysis, the Dual-Bingham model was first used to find the four model parameters $X_{0}=\left(\tau_{0}, \eta_{0}, \tau_{\infty}, \eta_{\infty}\right)$, which was then used as the initial guesses for the four model parameters in Worrall-Tuliani model. The lower and upper bonds of the four model parameters in Worrall-Tuliani model were specified by $0.9 X_{0}$ and $1.1 X_{0}$, respectively.

The four model parameters for all Hangzhou Bay mud samples are listed in Table 3 for Worrall-Tuliani model and Table 4 for Dual-Bingham model, respectively. Figure 1 shows the measured flow curves as well as the fitting curves given by both Worrall-Tuliani model and Dual-Bingham model. Figure 2 shows a comparison of Worrall-Tuliani model and Dual-Bingham model for mud sample A0 on log-log scale (left) and linear-linear scale (right), respectively. On the log-log plot the differences between the fitting curves and the measured data are magnified in low shear rate region. It can be observed that the shear stresses predicted by both models are slightly larger than those measured at low shear rate $\left(\dot{\gamma}<0.01 s^{-1}\right)$, especially for mud samples of high concentration, suggesting that the yield stresses be slightly over predicted by both models.

Table 3 Model parameters for Worrall-Tuliani model

\begin{tabular}{|c|c|c|c|c|c|}
\hline $\begin{array}{c}\text { Sample } \\
\text { sites }\end{array}$ & Sample & $\tau_{0}\left(N / m^{2}\right)$ & $\eta_{0}\left(N \cdot s / m^{2}\right)$ & $\tau_{\infty}\left(N / m^{2}\right)$ & $\eta_{\infty}\left(N \cdot s / m^{2}\right)$ \\
\hline \multirow{4}{*}{ East } & $\mathrm{A} 0$ & 38.659 & 25.360 & 133.939 & 0.070 \\
\cline { 2 - 6 } & $\mathrm{A} 1$ & 2.907 & 3.352 & 10.184 & 0.010 \\
\cline { 2 - 6 } & $\mathrm{A} 2$ & 1.600 & 4.000 & 4.225 & 0.004 \\
\cline { 2 - 6 } & $\mathrm{A} 3$ & 1.220 & 2.500 & 3.000 & 0.005 \\
\cline { 2 - 6 } & $\mathrm{A} 4$ & 0.800 & 1.500 & 1.632 & 0.002 \\
\hline \multirow{5}{*}{ West } & $\mathrm{B} 0$ & 40.000 & 196.570 & 182.745 & 1.225 \\
\cline { 2 - 6 } & $\mathrm{B} 1$ & 3.000 & 3.000 & 6.557 & 0.011 \\
\cline { 2 - 6 } & $\mathrm{B} 2$ & 2.000 & 1.643 & 4.556 & 0.006 \\
\cline { 2 - 6 } & $\mathrm{B} 3$ & 1.400 & 2.500 & 2.285 & 0.005 \\
\cline { 2 - 6 } & $\mathrm{B} 4$ & 0.799 & 1.500 & 1.333 & 0.005 \\
\cline { 2 - 6 } & $\mathrm{B} 5$ & 0.550 & 1.200 & 1.055 & 0.003 \\
\hline
\end{tabular}

Table 4 Model parameters for Dual-Bingham model

\begin{tabular}{|l|c|c|c|c|c|c|}
\hline Sample sites & Samples & $\tau_{0}\left(N / \mathrm{m}^{2}\right)$ & $\eta_{0}\left(N \cdot \mathrm{s} / \mathrm{m}^{2}\right)$ & $\tau_{\infty}\left(N / \mathrm{m}^{2}\right)$ & $\eta_{\infty}\left(N \cdot s / \mathrm{m}^{2}\right)$ & $\gamma_{c}(1 / s)$ \\
\hline \multirow{4}{*}{ East } & $\mathrm{A} 0$ & 38.659 & 25.360 & 133.939 & 0.070 & 9.3324 \\
\cline { 2 - 7 } & $\mathrm{A} 1$ & 2.907 & 3.352 & 10.184 & 0.010 & 4.5799 \\
\cline { 2 - 7 } & $\mathrm{A} 2$ & 1.600 & 4.000 & 4.225 & 0.004 & 1.5646 \\
\cline { 2 - 7 } & $\mathrm{A} 3$ & 1.220 & 2.500 & 3.000 & 0.005 & 1.2434 \\
\cline { 2 - 7 } & $\mathrm{A} 4$ & 0.800 & 1.500 & 1.632 & 0.002 & 0.6273 \\
\hline \multirow{4}{*}{ West } & $\mathrm{B} 0$ & 40.000 & 196.570 & 182.745 & 1.225 & 9.4943 \\
\cline { 2 - 7 } & $\mathrm{B} 1$ & 3.000 & 3.000 & 6.557 & 0.011 & 4.5487 \\
\cline { 2 - 7 } & $\mathrm{B} 2$ & 2.000 & 1.643 & 4.556 & 0.006 & 3.4522 \\
\cline { 2 - 7 } & $\mathrm{B} 3$ & 1.400 & 2.500 & 2.285 & 0.005 & 1.5081 \\
\cline { 2 - 7 } & $\mathrm{B} 4$ & 0.799 & 1.500 & 1.333 & 0.005 & 0.9041 \\
\cline { 2 - 7 } & $\mathrm{B} 5$ & 0.550 & 1.200 & 1.055 & 0.003 & 0.8807 \\
\hline
\end{tabular}

The Dual-Bingham true yield stress $\tau_{0}$ and initial viscosity $\eta_{0}$ as functions of volumetric concentration $C_{V}$ are shown in Fig. 3(a) and Fig. 3(b), respectively. The mud samples include Hanzhou Bay mud, Lianyun Gang mud (Huhe et al., 1994b), Aspen mud (O’Brien and Julien, 1988), and Kaolinite clay (Komatina and Jovanovic, 1997). Some properties of the mud samples listed above are given in Table 5. 
Only the fitting curves for Hangzhou Bay mud are shown in Fig. 3. The Dual-Bingham true yield stresses $\left(\tau_{0}\right)$ of Hangzhou Bay mud are close to those of Aspen Pit 1 mud and Aspen Pit 2 , but one order of magnitude larger than those of Aspen natural mud and Kaolinite clay. The Dual-Bingham initial viscosities $\left(\eta_{0}\right)$ of Hangzhou Bay mud are close to those of Liangyun Gang mud, Aspen Pit 1 mud, but two orders of magnitude larger than those of Aspen natural mud and Aspen Pit 2 for $C_{V} \approx 0.35$. Even though great scatter can be observed in Fig. 3, an exponential dependence of $\tau_{0}$ and $\eta_{0}$ on the sediment volume concentration, $C_{V}$, is evident, suggesting that the Dual-Bingham true yield stress and initial viscosity can be expressed approximately by
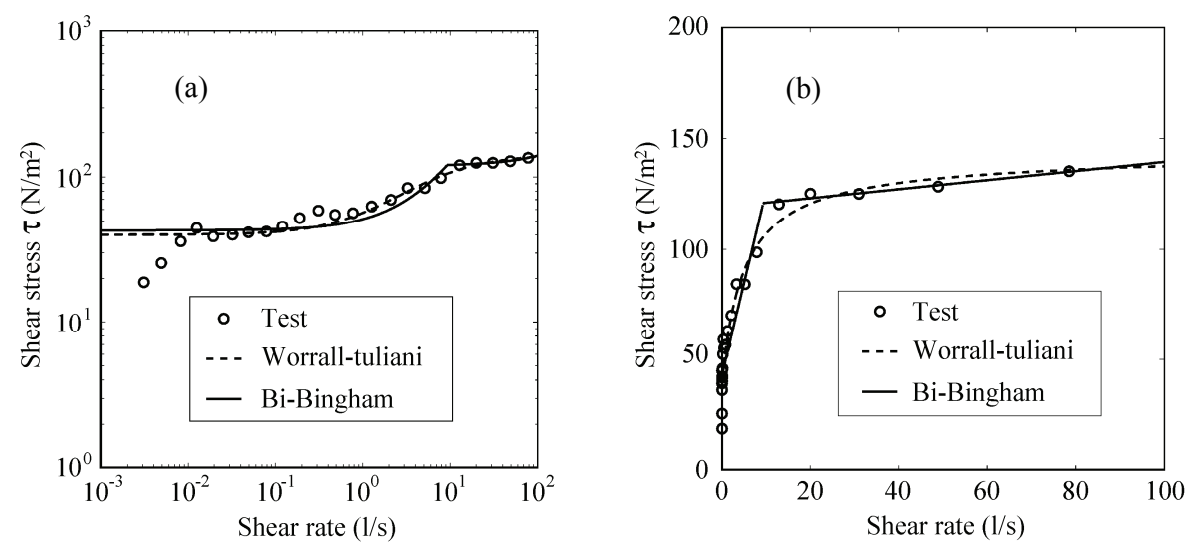

Fig. 2 A comparison of Worrall-Tuliani model and Dual-Bingham model on log-scale plot as well as linear-scale plot for the mud sample A0 in Hangzhou Bay

Table 5 Some properties of mud samples*

\begin{tabular}{|l|c|c|c|c|}
\hline Samples & Clay $(\%)$ & $D_{16}(\mathrm{~mm})$ & $D_{50}(\mathrm{~mm})$ & $D_{84}(\mathrm{~mm})$ \\
\hline Aspen Pit 1 & 31.3 & 0.001 & 0.011 & 0.032 \\
\hline Aspen natural soil source & 27.0 & 0.001 & 0.012 & 0.028 \\
\hline Lianyun Gang at high-tide level & 37 & 0.0022 & 0.009 & 0.055 \\
\hline Lianyun Gang at low tide level & 80 & 0.00085 & 0.002 & 0.0055 \\
\hline Kaolinite clay & 100 & - & 0.006 & - \\
\hline
\end{tabular}

* Data source: Aspen mud - O’Brien and Julien (1988); Lianyun Gang mud--Huhe et al. (1994b); Kaolinite clayKomatina and Jovanovic (1997)
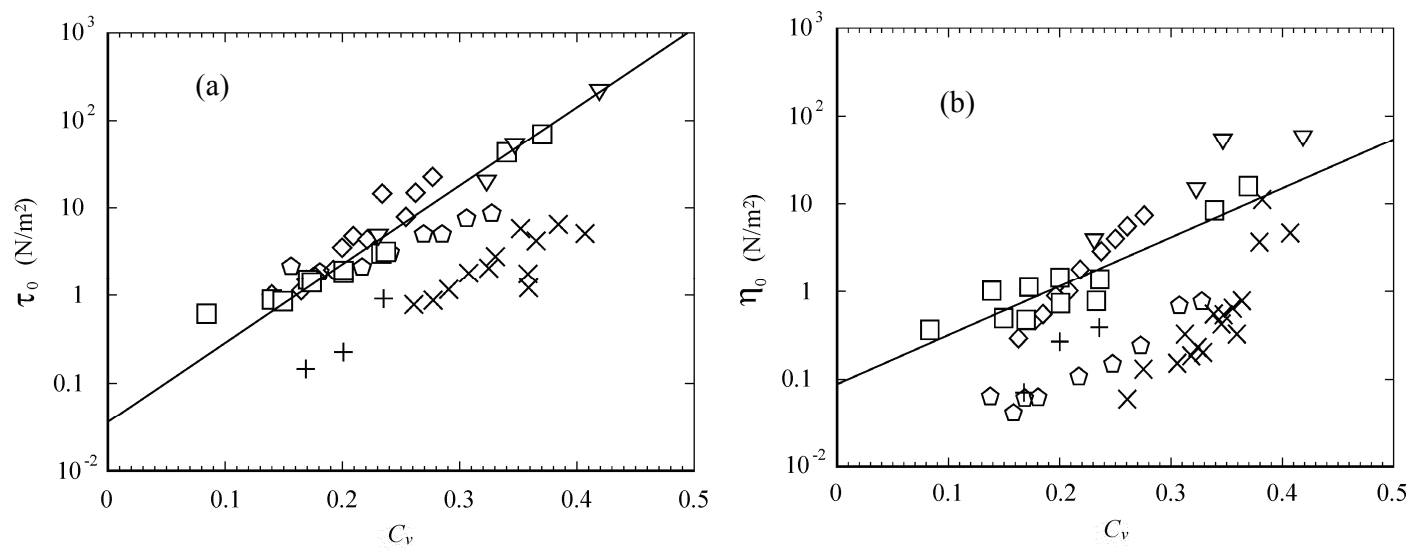

Fig. 3 Dual-Bingham true yield stress and initial viscosity. Symbols: Hangzhou Bay (squares), Lianyun Gang (down triangles), Aspen Pit 1 (diamonds), Aspen Pit 2 (hexagram), Aspen natural soil source (x), and Kaolinite (+). Fitting curves: Hangzhou Bay (solid line) 


$$
\tau_{0}=\alpha_{1} \exp \left(\beta_{1} C_{V}\right), \quad \eta_{0}=\alpha_{2} \exp \left(\beta_{2} C_{V}\right),
$$

where $\alpha_{1}, \beta_{1}, \alpha_{2}$ and $\beta_{2}$ are fitting parameters and given in Table 6 for Dual-Bingham model.

The Dual-Bingham apparent yield stress $\tau_{\infty}$ and apparent viscosity $\eta_{\infty}$ as functions of volumetric concentration are shown in Figs. 4(a) and 4(b), respectively. The mud samples include Hangzhou Bay mud, Lianyun Gang mud (Huhe et al., 1994b), and Kaolinite clay (Komatina and Jovanovic, 1997). Only the fitting curve for Hangzhou Bay mud is shown in Fig. 4. The Dual-Bingham apparent yield stresses of Hangzhou Bay mud are close to those of Liangyun Gang mud and Kaolinite water-clay mixtures, except in the range of $C_{V}<0.2$, where yield stress of Kaolinite water-clay mixture tends to be one order of magnitude smaller. The apparent viscosities of Hangzhou Bay mud are close to those of Kaolinite waterclay mixtures, but about one order of magnitude larger than those of Lianyun Gang mud. Again, the exponential dependency of the apparent yield stress $\tau_{\infty}$ and apparent viscosity $\eta_{\infty}$ on the sediment volume concentration, $C_{V}$, is evident, suggesting that they can be expressed approximately by

$$
\tau_{\infty}=\alpha_{3} \exp \left(\beta_{3} C_{V}\right), \eta_{\infty}=\alpha_{\infty} \exp \left(\beta_{\infty} C_{V}\right),
$$

where $\alpha_{3}, \beta_{3}, \alpha_{4}$ and $\beta_{4}$ are fitting parameters and given in Table 6 for Dual-Bingham model.

Table 6 Empirical fitting parameters for Dual-Bingham model

\begin{tabular}{|c|c|c|c|c|c|c|}
\hline & $\begin{array}{c}\text { Huhe } \\
(1994 \mathrm{~b}): \\
\text { Lianyun } \\
\text { Gang }\end{array}$ & $\begin{array}{c}\text { Hangzhou } \\
\text { Bay }\end{array}$ & $\begin{array}{c}\text { O'Brien and } \\
\text { Julien } \\
(1988): \\
\text { Aspen Pit1 }\end{array}$ & $\begin{array}{c}\text { O'Brien and } \\
\text { Julien } \\
(1988): \\
\text { Aspen Pit2 }\end{array}$ & $\begin{array}{c}\text { O'Brien and } \\
\text { Julien(1988), } \\
\text { Aspen natural } \\
\text { soil source }\end{array}$ & $\begin{array}{c}\text { Komatina and } \\
\text { Jovanovic } \\
(1997), \\
\text { Kaolinite }\end{array}$ \\
\hline$D_{50}(\mathrm{~mm})$ & $9.00 \mathrm{E}-3$ & $9.7 \mathrm{E}-3$ & $1.10 \mathrm{E}-2$ & $1.10 \mathrm{E}-2^{\mathrm{a}}$ & $1.60 \mathrm{E}-2$ & $6.00 \mathrm{E}-3$ \\
\hline Clay $(\%)$ & 37.00 & 31.00 & 31.30 & $31.30^{\mathrm{a}}$ & 27.00 & $10.00 \mathrm{E}+1$ \\
\hline$\rho_{s}\left(\mathrm{~kg} / \mathrm{m}^{3}\right)$ & $27.50 \mathrm{E}+2$ & $27.00 \mathrm{E}+2$ & - & - & - & $26.50 \mathrm{E}+2^{\mathrm{b}}$ \\
\hline$\alpha_{1}\left(\mathrm{~N} / \mathrm{m}^{2}\right)$ & $3.64 \mathrm{E}-02$ & $6.58 \mathrm{E}-02$ & $2.69 \mathrm{E}-02$ & $3.45 \mathrm{E}-01$ & $2.43 \mathrm{E}-02$ & $1.09 \mathrm{E}-03$ \\
\hline$\beta_{1}$ & $2.10 \mathrm{E}+01$ & $1.79 \mathrm{E}+01$ & $2.40 \mathrm{E}+01$ & $9.58 \mathrm{E}+00$ & $1.35 \mathrm{E}+01$ & $2.78 \mathrm{E}+01$ \\
\hline$\alpha_{2}\left(\mathrm{~N} . \mathrm{s} / \mathrm{m}^{2}\right)$ & $1.66 \mathrm{E}-01$ & $8.67 \mathrm{E}-02$ & $2.44 \mathrm{E}-03$ & $4.66 \mathrm{E}-03$ & $9.03 \mathrm{E}-06$ & $1.15 \mathrm{E}-03$ \\
\hline$\beta_{2}$ & $1.36 \mathrm{E}+01$ & $1.29 \mathrm{E}+01$ & $2.95 \mathrm{E}+01$ & $1.51 \mathrm{E}+01$ & $3.21 \mathrm{E}+01$ & $2.54 \mathrm{E}+01$ \\
\hline$\alpha_{3}\left(\mathrm{~N} / \mathrm{m}^{2}\right)$ & $2.83 \mathrm{E}-02$ & $7.81 \mathrm{E}-02$ & - & - & - & $2.45 \mathrm{E}-03$ \\
\hline$\beta_{3}$ & $2.39 \mathrm{E}+01$ & $2.07 \mathrm{E}+01$ & - & - & - & $3.29 \mathrm{E}+01$ \\
\hline$\alpha_{4}\left(\mathrm{~N} . \mathrm{s} / \mathrm{m}^{2}\right)$ & $2.83 \mathrm{E}-05$ & $1.84 \mathrm{E}-04$ & - & - & - & $5.98 \mathrm{E}-04$ \\
\hline$\beta_{4}$ & $2.02 \mathrm{E}+01$ & $1.95 \mathrm{E}+01$ & - & - & - & $1.74 \mathrm{E}+01$ \\
\hline$\alpha_{5}(1 / \mathrm{s})$ & $3.41 \mathrm{E}-02$ & $2.53 \mathrm{E}-01$ & & & & 1.444 \\
\hline$\beta_{5}$ & $1.31 \mathrm{E}+01$ & $1.05 \mathrm{E}+01$ & & & & 9.17 \\
\hline${ }^{\mathrm{a}}$ The same values for Pit 1 were used for Pit 2. & \\
\hline${ }^{\mathrm{b}}$ This value was calculated from the specific density of 2.65. &
\end{tabular}

It can be concluded from Figs. 3 and 4 that the simple exponential dependence of the yield stress as well as the mud viscosity on the sediment volume concentration provides a satisfactory representation for all mud samples examined here, even though the coefficients $\alpha_{j}, \beta_{j}$ vary from one mud sample to another. Physically, sediment volume concentration $C_{V}$ reflects the distance between the sediment particles; that is, a decrease in $C_{V}$ will result in an increase in the distance between the sediment particles and thus weaken the forces between sediment particles. We just remark here that the true yield stresses and the apparent yield stresses reported here are determined by fitting the measured flow curves with the same rheological model and thus can be compared with each other. Since the yield stress determined by extrapolation method depends strongly on the rheological model used to perform the extrapolation, we avoided comparing our results with other published yield stresses determined by other rheological models. 

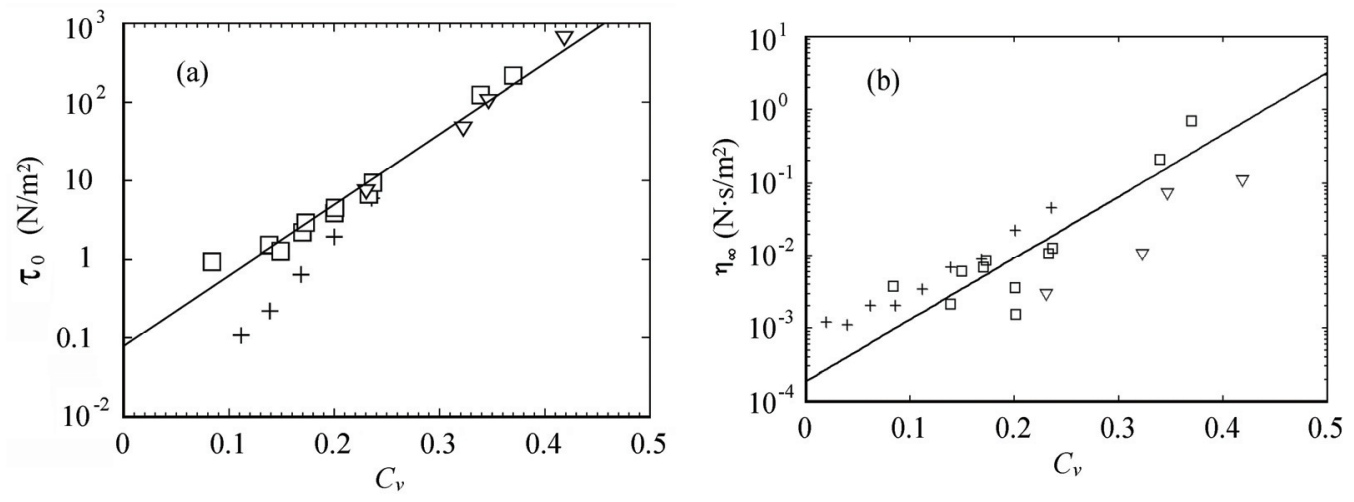

Fig. 4 Dual-Bingham apparent yield stress and apparent viscosity. Symbols: Hangzhou Bay (squares), Lianyun Gang (down triangles), and Kaolinite (+). Fitting curves: Hangzhou Bay (solid line)

\subsection{Critical shear rates}

For Dual-Bingham model, a critical shear rate exists at which two fitting curves intersect. This critical shear rate indicates the starting point of shear-thinning (Whitehouse et al., 2000). The critical shear rate as a function of sediment volume concentration is shown in Fig. 5 for Hangzhou Bay mud, Lianyun Gang mud (Huhe et al., 1994b), and Kaolinite (Komatina and Jovanovic, 1997). It can be seen that the critical shear rate fits well with the following exponential function,

$$
\dot{\gamma}_{c}=\alpha_{5} \exp \left(\beta_{5} C_{V}\right),
$$

where the values of $\alpha_{5}$ and $\beta_{5}$ are also listed in Table 6. Again only the fitting curve for Hangzhou Bay mud is shown in Fig. 5.

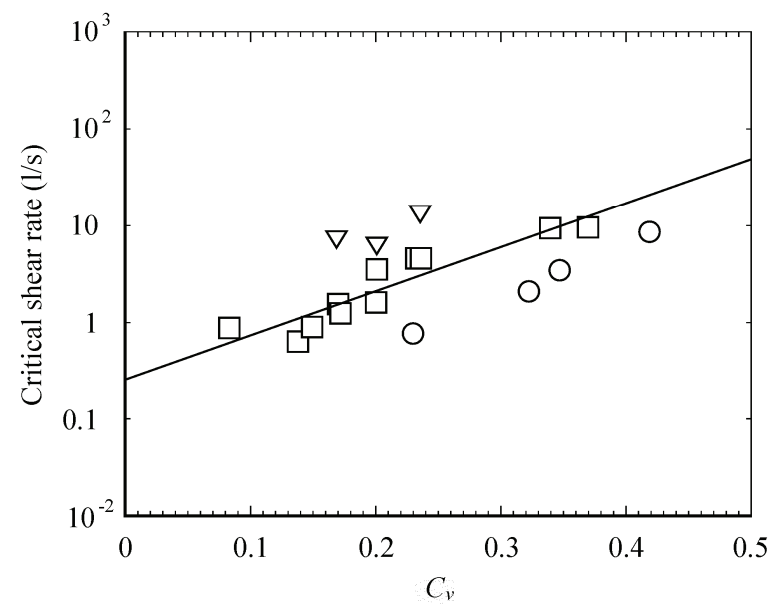

Fig. 5 Critical shear rate for Dual-Bingham model. Hangzhou Bay (squares), Lianyun Gang (circles), and Kaolinite (down triangles). Fitting curve: Hangzhou Bay mud (solid line)

4.3 Use of Dual-Bingham model in numerical models

Figure 6(a) shows a comparison of the shear stress measured and the one predicted by Dual-Bingham model with the four model parameters given in Table 3; Fig. 6(b) shows another comparison of the shear stress measured and the one predicted by Dual-Bingham model with the four model parameters being calculated by using Eqs. (11) and (12), and with parameters $\alpha_{j}$ and $\beta_{j}$ being given in Table 6. It can be seen that the empirical Eqs. (11) and (12) predict the four model coefficients reasonably well over a wide range of shear rate for all mud samples examined here. Therefore, we tentatively conclude that the proposed Dual-Bingham rheological model (Eqs. (6), (11)-(12)) can be incorporated in numerical models for steady mudflows. 
4.4 Rheological properties of oscillatory mudflows

The measured elastic shear moduli of the mud samples taken from the two sites in Hangzhou Bay are shown in Fig. 7, and the measured dynamic viscosities are shown in Fig. 8. It can be seen that both $G^{\prime}$ and $\eta$ vary with frequency of the forced oscillating motion, implying that dynamic rheological model described by Eq. (8) is nonlinear in nature. However, $G^{\prime}$ varies only slightly with the frequency in low frequency range $(0.2<\omega<6 \mathrm{rad} / \mathrm{s})$, except for mud sample $\mathrm{A}_{1}$. For Caland mud and China clay mixed with tap water, Van Kessel and Blom (1998) showed that both the elastic shear modulus and loss modulus in the range of $0.628<\omega<6.28 \mathrm{rad} / \mathrm{s}$ are insensitive to oscillation frequency. Our results of elastic shear modulus are consistent with the findings of Van Kessel and Blom (1998).
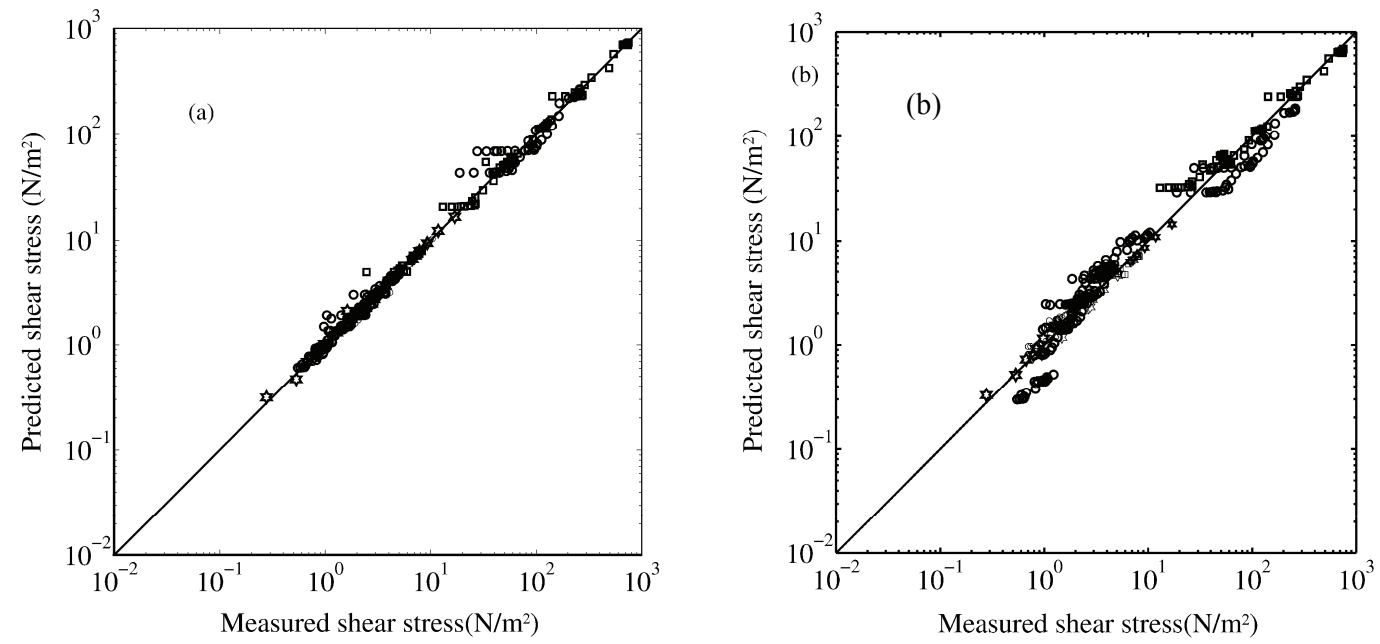

Fig. 6 Comparison of the shear stresses measured and predicted by Dual-Bingham model. Symbols: Hangzhou Bay (circles), Lianyun Gang (squares), and Kaolinite (hexagram)
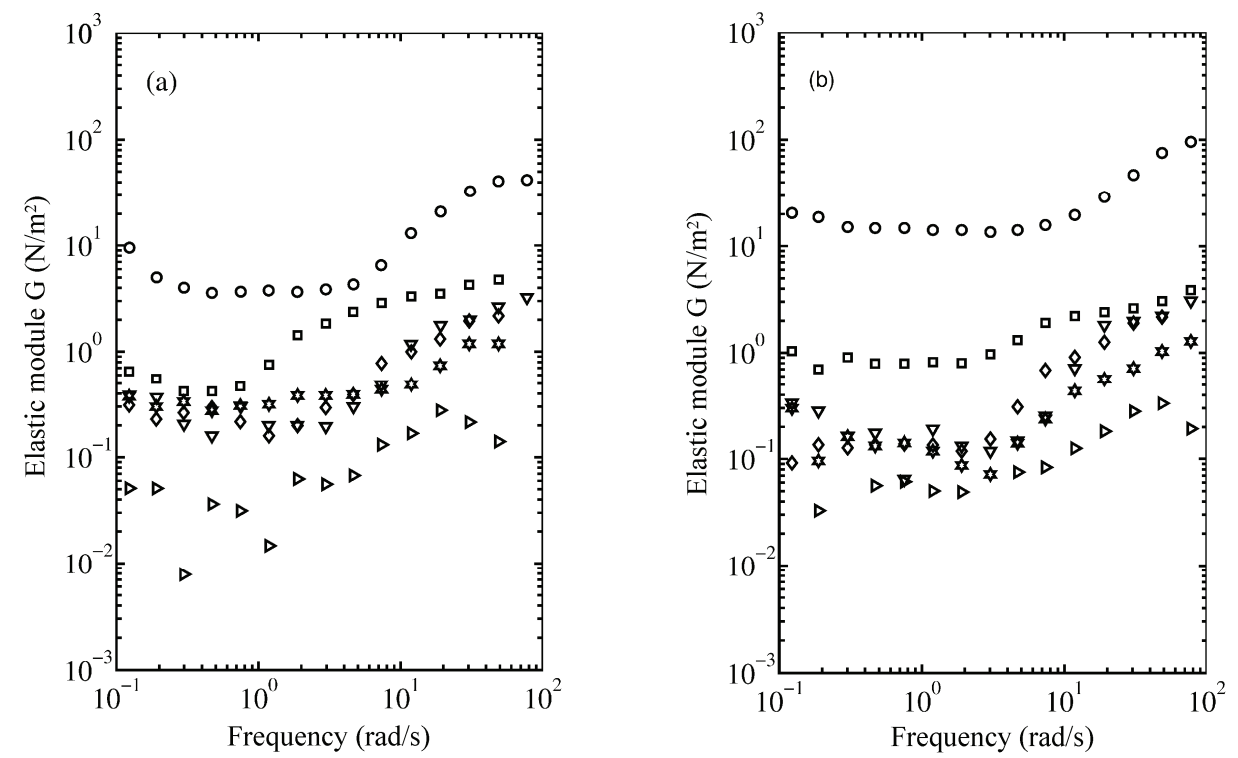

Fig. 7 Elastic modulus of natural mud from the East channel (a) and the West channel (b). For the East channel: $C v=0.34$ (squares), 0.237 (circles), 0.201(right triangles), 0.173 (left triangles), and 0.136(hexagram); For the West channel: $C v=0.37$ (squares), 0.233 (circles), 0.202(right triangles), 0.171 (left triangles), and 0.150 (hexagram), and 0.084 (down triangles) 
Ocean waves near shore normally have a period about 3-8s, or an angular frequency about $\omega=0.7-1.5$ $\mathrm{rad} / \mathrm{s}$. The effects of the muddy seabed on water waves above will become weaker when waves become shorter or water gets deeper. After compiling the data for the east channel mud and the west channel mud, empirical expressions for the elastic modulus at $\omega=0.8,1.2,1.5 \mathrm{rad} / \mathrm{s}$ are given as follows
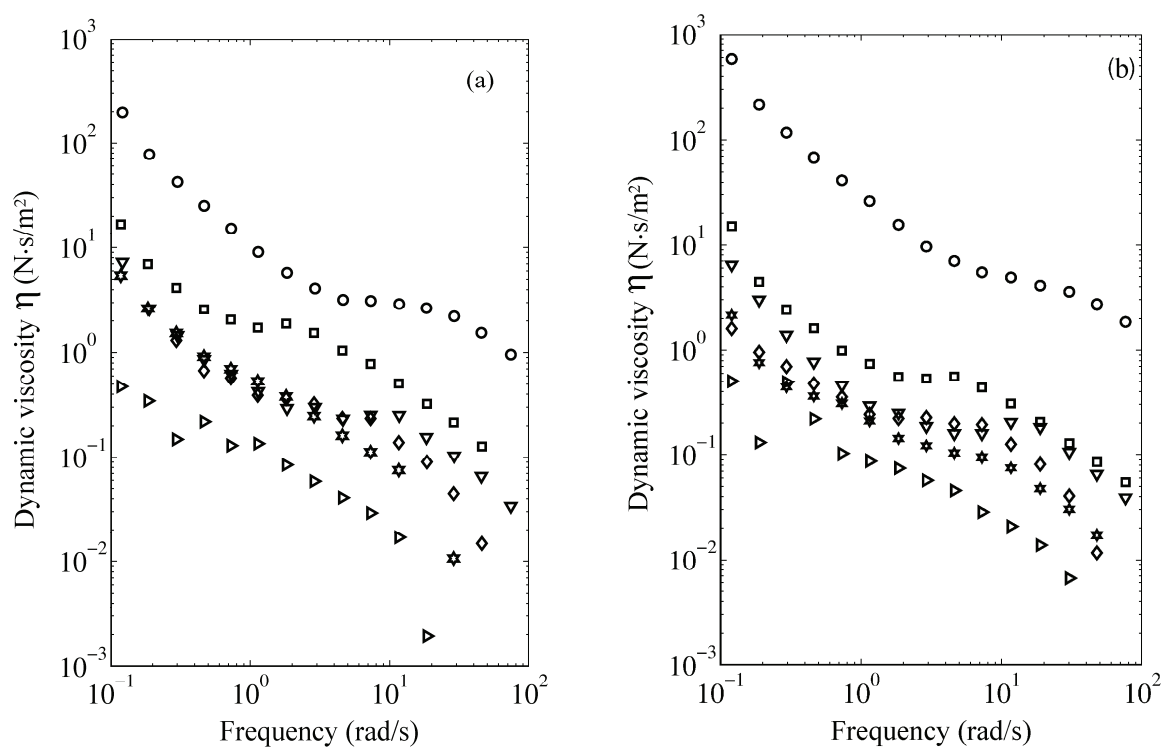

Fig. 8 Dynamic viscosity of natural mud from the East channel (a) and the West channel (b). For the East channel: $C v=0.34$ (squares), 0.237 (circles), 0.201 (right triangles), 0.173 (left triangles), and 0.136(hexagram); For the West channel: $C v=0.37$ (squares), 0.233 (circles), 0.202 (right triangles), 0.171 (left triangles), and 0.150 (hexagram), and 0.084 (down triangles)

$$
\begin{aligned}
& G_{0.8}^{\prime}=0.008 e^{18.43 C_{V}}, \\
& G_{1.2}^{\prime}=0.0059 e^{19.96 C_{V}}, \\
& G_{1.5}^{\prime}=0.0074 e^{19.17 C_{V}},
\end{aligned}
$$

The coefficients in the above expressions for $G_{0.8}^{\prime}, G_{1.2}^{\prime}$ and $G_{1.5}^{\prime}$ suggest that a constant elastic modulus may be used for the range of frequency of practical interests.

In the frequency range $0.1<\omega<100 \mathrm{rad} / \mathrm{s}$ the dynamic viscosity generally decreases with increasing frequency due to the shear-thinning effect. However, in the narrow frequency range of practical interest $0.6<\omega<2 \mathrm{rad} / \mathrm{s}$, the change of the dynamic viscosity with frequency $\omega$ is insignificant. Empirical expressions for the dynamic viscosity at $\omega=0.8,1.2,1.5 \mathrm{rad} / \mathrm{s}$ are given as follows

$$
\begin{aligned}
& \eta_{0.8}=0.0198 e^{19.07 C_{V}}, \\
& \eta_{1.2}=0.0181 e^{17.71 C_{V}}, \\
& \eta_{1.5}=0.0160 e^{17.38 C_{V}},
\end{aligned}
$$

As the empirical formulas (14)-(19) are derived from our experiments, it is worth mentioning that these formulas are expected to be valid for mud of similar properties given in Table 1 and of mass concentration in the range $0.07<C_{V}<0.37$.

Figure 9 shows the measured $G_{0.8}^{\prime}$ and $\eta_{0.8}$ together with the fitting curves given by Eqs. (14) and (17). Good agreements between the data and fitting curves are also found for elastic shear modulus and dynamic viscosity at other two frequencies. Again it is found that the simple exponential dependence of 
the elastic modulus and dynamic viscosities on sediment volume concentration works for the Hangzhou Bay mud.
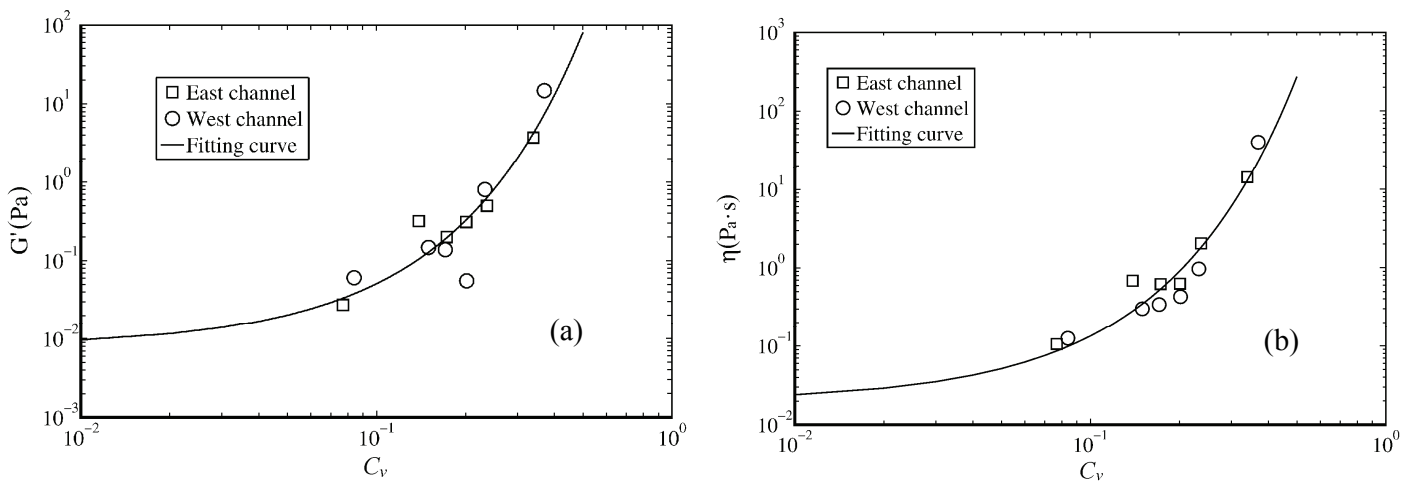

Fig. 9 Variation of elastic modulus and dynamic viscosity with sediment volume concentration at frequency $\omega=0.8 \mathrm{rad} / \mathrm{s}$. The fitting curves are obtained by Eqs. (14) and (17)

Figure 10 compares the elastic shear modulus of Hangzhou Bay mud (averaged over $0.8<\omega<1.5 \mathrm{rad} / \mathrm{s}$ ) to that of Lianyun Gang mud (Huhe et al., 1994b). The elastic modulus of Lianyun Gang mud in low concentration range is only slightly greater than that of Hangzhou Bay mud. However, the elastic modulus of Lianyun Gang mud in high concentration range is at least one order of magnitude larger than that of Hangzhou Bay mud.

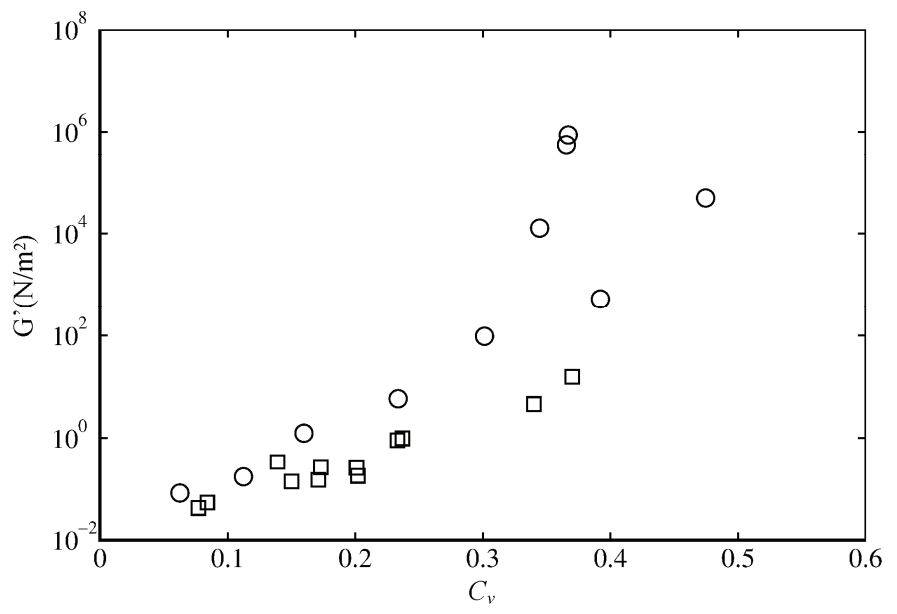

Fig. 10 Comparison of the elastic modulus for Hangzhou Bay mud (squares) and Lianyun-Gang mud (circles)

Jiang and Mehta (1995) reported their measured elastic shear modulus and dynamic viscosity, and analyzed their results using a three parameter visco-elastic mode. The volume concentrations of the mud samples reported in their paper are in the range of $C_{V}=0.07 \sim 0.17$, which is much smaller than those of Hangzhou Bay mud. A comparison of the elastic shear modulus $\left(G_{0.8}^{\prime}, G_{1.5}^{\prime}\right)$ and dynamic viscosity $\left(\eta_{0.8}, \eta_{1.5}\right)$ of three mud samples given in Jiang and Mehta (1995) and those of Hangzhou Bay mud is summarized in Table 7, where the results of Jiang and Mehta (1995) are calculated with the empirical equations given in their paper. The volume concentrations are chosen to be either 0.11 or 0.12 for comparisons between the results. Both the elastic shear modulus and dynamic viscosity of the mud samples reported in Jiang and Mehta (1995) are several orders of magnitude larger than those of Hangzhou Bay mud. One possible factor that might contribute to such large differences observed in Table 
7 is the difference in the median grain size-AK mud and KI mud both are much finer than Hangzhou Bay mud. Other possible factors can be the high organic content in $\mathrm{OK}$ mud and the thixotropic attapulgite in AK mud.

Table 7 Comparison of shear modulus and dynamic viscosity from different sources ${ }^{(a)}$

\begin{tabular}{|c|c|c|c|c|c|c|}
\hline & $D_{50}(\mu \mathrm{m})$ & $C_{V}$ & $G_{0.8}^{\prime}(\mathrm{Pa})$ & $G_{1.5}^{\prime}(\mathrm{Pa})$ & $\eta_{0.8}(\mathrm{~Pa} / \mathrm{s})$ & $\eta_{1.5}(\mathrm{~Pa} \cdot \mathrm{s})$ \\
\hline Hangzhou Bay & $9.7-11.0$ & 0.12 & 0.073 & 0.074 & 0.195 & 0.129 \\
\hline KI & 2 & 0.12 & $1.036 \times 10^{4}$ & $1.252 \times 10^{4}$ & $3.655 \times 10^{3}$ & $1.879 \times 10^{3}$ \\
\hline OK & 9 & 0.11 & $3.608 \times 10^{2}$ & $3.990 \times 10^{2}$ & $1.381 \times 10^{2}$ & $0.709 \times 10^{2}$ \\
\hline AK & 1 & 0.12 & $4.526 \times 10^{3}$ & $5.036 \times 10^{3}$ & $1.724 \times 10^{3}$ & $0.789 \times 10^{3}$ \\
\hline
\end{tabular}

${ }^{\text {(a) }}$ Results for KI, OK and AK mud are from Jiang and Mehta(1995). KI=Kerala, India mud; OK=Okeechobee mud; $\mathrm{AK}=$ Attapulgite + kaolinite

\section{Conclusions}

The rheological properties of steady and oscillatory mudflows in Hangzhou Bay, China, were studied experimentally using RMS-605 rheometer. After analyzing Hangzhou Bay mud and other mud samples published in literature with both Dual-Bingham model and Worall-Tuliani model, we find that the simple Dual-Bingham model is easier to implement than Worrall-Tuliani model. Our analysis also shows that both steady and dynamic rheological properties can be expressed as appropriate exponential functions of sediment volume concentration, with empirical parameters being dependent on size distribution, clay content, organic content, and mineral composition.

\section{Acknowledgement}

The writers would like thank two anonymous reviewers for their valuable comments, which have greatly improved the quality of the manuscript. The writers would also like to express our thanks to the LianYun-Gang Port Construction Authority and its former Director, Mr. Liu Jin, and to the Design and Research Institute of Shanghai Navigation Channel and its former chief engineer, Mr. Xueliang Cheng, for their support to our project. The opinions described in this paper do not necessarily reflect the standing of the funding agencies.

\section{References}

Bai Y. C., Ng C. O., Shen H. T., and Wang S. Y. 2002, Rheological properties and incipient motion of cohesive sediment in the Haihe Estuary of China. China Ocean Engineering, Vol. 16, No. 4, pp. 483-498.

Barnes H. A., Hutton J. F., and Walters K. 1989, An Introduction to Rheology. Elsevier.

Casson N. 1957, A flow equation for pigment-oil suspensions of the printing ink type. Rheology of Disperse Systems, University College of Swansea, Sept. 1957, pp. 84-105.

Chen S. L. and Gu G. C. 2000, Modeling the concentration of suspended sediment in Hangzhou Bay. Sediment Research, Vol. 5, p. 6 (in Chinese).

Coussot P. 1997, Mudflow Rheology and Dynamics. A. A. Balkema, Rotterdam. p. 255.

Coussot P. 2007, Rheophysics of pastes: a review of microscopic modelling approaches. Soft Matter, Vol. 3, pp. $528-540$.

Foda M. A., Hunt J. R., and Chou H. T. 1993, A nonlinear model for the fluidization of marine mud by waves. Journal of Geophysical Research, Vol. 98, No. C4, pp.7039-7047.

Huang X. and Garcia M. H. 1998, A Herschel-Bulkley model for mud flow down a slope. Journal of Fluid Mechanics, Vol. 374, pp.305-333.

Huhe Aode and Huang Z. H. 1994a, Experimental study of rheology of Hangzhou Bay mud. International report IMCAS STR-94021, Institute of Mechanics, Chinese Academy of Sciences (in Chinese).

Huhe Aode, Huang Z. H., Zhang Y. B., and Jin L. 1994b, Rheology of mudflow in Lian-yun-gang Port. Mechanics and Practice, Vol. 16, No. 1, pp. 21-24 (in Chinese).

James A. E., Williams D. J. A., and Williams P. R. 1987, Direct measurement of static yield properties of cohesive suspensions. Rheologica Acta, Vol. 26, No. 5, pp.437-446.

Jiang F. and Mehta A. J. 1995, Mudbanks of the southwest coast of India IV: Mud viscoelastic properties. Journal of Coastal Research, Vol. 11, No. 3, pp.918-926.

Jin L. and Yu Z. Y. 1999, A dynamic approach to the prediction of the refill of the navigation channel in mud bed: A case study for Hangzhou Bay. Sediment Research, Vol. 5, p. 9 (in Chinese).

Jorgen F. and Deigaard R. 1992, Mechanics of Coastal Sediment Transport. World Scientific Publishing.

International Journal of Sediment Research, Vol. 24, No. 4, 2009, pp. 410-424 
Julien P. Y. and Lan Y. Q. 1991, Rheology of hyperconcentrations. Journal of Hydraulic Engineering, Vol. 117, No. 3, pp.346-353.

Komatina D. and Jovanovic M. 1997, Experimental study of steady and unsteady free surface flows with water-clay mixtures. Journal of Hydraulics Research, Vol. 35, No. 5, pp. 579-590.

Liu K. F. and Mei C. C. 1989, Slow spreading of a sheet of Bingham fluid on an inclined plane. Journal of Fluid Mechanics, Vol. 207, pp. 505-529.

Maa P. Y. and Mehta A. J. 1988, Soft mud properties: Voigt model. Journal of Waterways, Port, Coastal and Ocean Engineering, Vol. 114, pp. 765-770.

Maa P. Y. and Mehta A. J. 1990, Soft mud response to water waves. Journal of Waterway, Port, Coastal and Ocean Engineering, Vol. 116, No. 5, pp. 634-650.

Malcherek A., Markofsky M., Zielke W., Peltier E., Normant C. Le, Teisson C., Cornelisse J., Molinaro P., Corti S., and Grego G. 1996, Three dimensional numerical modeling of cohesive sediment transport processes in estuarine environments. Final Report to the EC Contract MAS2-CT92-0013.

Mayne D. A., Usmani A. S., and Crapper M. 2002, An adaptive finite element solution for cohesive sediment transport. Fine Sediment Dynamics in Marine Environment, Winterwerp, J. C., and Kranenburg, C. (editors), pp.627-641.

Mei C. C. and Liu K. -F. 1987, A Bingham-plastic model for a muddy seabed under long waves. Journal of Geophysical Research (Ocean), Vol. 92, pp. 14581-14594.

Ng C. O. and Zhang X. Y. 2007, Mass transport in water waves over a thin layer of soft viscoelastic mud. Journal of Fluid Mechanics, Vol. 573, pp.105-130.

O’ Brien J. S. and Julien P. Y. 1988, Laboratory analysis of mudflow properties. Journal of Hydraulics Engineering, Vol. 114, No. 8, pp. 877-887.

Piedra-Cueva I. 1993, On the response of a muddy bottom to surface water waves. Journal of Hydraulic Research, Vol. 31, No. 5, pp. 681-696.

Shibayama T. and An N. N. 1993, A visco-elastic-plastic model for wave mud interaction. Coastal Engineering in Japan, Vol. 36, No. 1, pp. 67-89.

Shibayama T. and Bijker E. W. 1989, Mass transport velocity in mud layer due to progressive waves. Journal of Waterway, Port, Coastal and Ocean Engineering, Vol. 115, No. 5, pp. 614-633.

Song D. Y. and Jiang T. Q. 1998, Study on the constitutive equation with fractional derivative for the viscoelastic fluids - Modified Jeffreys model and its application. Rheologica Acta, Vol. 37, No. 5, pp. 512-517.

Toorman E. A. 1994, An analytical solution for the velocity and shear rate distribution of non-ideal Bingham fluids in concentric cylinder viscometers. Rheologica Acta, Vol. 33, pp. 193-202.

Van Kessel T. and Blom C. 1998, Rheology of cohesive sediments: comparison between a natural and an artificial mud. Journal of Hydraulic Research, Vol. 36, No. 4, pp. 591-612.

Whitehouse R., Soulsby R., Roberts W., and Mitchener H. 2000, Dynamics of Estuarine Muds: A Manual for Practical Applications, Thomas Telford.

Worrall W. E. and Tuliani S. 1964, Viscosity changes during the ageing of clay-water suspensions. Transactions of the British Ceramic Society, Vol. 63, pp. 167-185.

Zhang Q. H., Wai O. W. H., and Zhao Z. D. 2007, Estimation of mud rheological parameters using genetic algorithm for a two-layer wave-mud system. Estuarine and Coastal Fine Sediments Dynamics, Maa, J. P.-Y., Sanford, L. P. and Schoellhamer, D. H. (editors), pp. 263-275. 